\title{
Comparing antibiotic self-medication in two socio-economic groups in Guatemala City: a descriptive cross-sectional study
}

\author{
Brooke M Ramay ${ }^{1 * \dagger}$, Paola Lambour ${ }^{1 \dagger}$ and Alejandro Cerón ${ }^{2}$
}

\begin{abstract}
Background: Self-medication with antibiotics may result in antimicrobial resistance and its high prevalence is of particular concern in Low to Middle Income Countries (LMIC) like Guatemala. A better understanding of self-medication with antibiotics may represent an opportunity to develop interventions guiding the rational use of antibiotics. We aimed to compare the magnitude of antibiotic self-medication and the characteristics of those who self-medicate in two pharmacies serving disparate socio-economic communities in Guatemala City.
\end{abstract}

Methods: We conducted a descriptive, cross-sectional study in one Suburban pharmacy and one City Center pharmacy in Guatemala City. We used a questionnaire to gather information about frequency of self-medication, income and education of those who self-medicate. We compared proportions between the two pharmacies, using two-sample z-test as appropriate.

Results: Four hundred and eighteen respondents completed the survey (221 in the Suburban pharmacy and 197 in the City Center pharmacy). Most respondents in both pharmacies were female (70\%). The reported monthly income in the suburban pharmacy was between $\$ 1,250.00-\$ 2,500.00$, the city-center pharmacy reported a monthly income between $\$ 125.00-\$ 625.00$ ( $p<0.01$ ). Twenty three percent of Suburban pharmacy respondents and 3\% in the City Center pharmacy completed high school $(p<0.01)$. Proportion of self-medication was $79 \%$ in the Suburban pharmacy and $77 \%$ in City Center pharmacy. In both settings, amoxicillin was reported as the antibiotic most commonly used.

Conclusions: High proportions of self-medication with antibiotics were reported in two pharmacies serving disparate socio-economic groups in Guatemala City. Additionally, self-medicating respondents were most often women and most commonly self-medicated with amoxicillin. Our findings support future public health interventions centered on the regulation of antibiotic sales and on the potential role of the pharmacist in guiding prescription with antibiotics in Guatemala.

Keywords: Self-medication, Guatemala, Antibiotic use, Socio-economic factors, Role of the pharmacist

\section{Background}

Self-medication with antibiotics occurs worldwide, fostering antibiotic misuse and antimicrobial resistance. The World Health Organization (WHO) recently reported alarming levels of resistance to penicillin, fluoroquinolones and third generation cephalosporins in member countries [1]. The misuse of antibiotics poses a serious risk to

\footnotetext{
* Correspondence: bramay@uvg.edu.gt

${ }^{\dagger}$ Equal contributors

'Department of Pharmaceutical Chemistry, Universidad del Valle de Guatemala, Guatemala City, Guatemala

Full list of author information is available at the end of the article
}

infectious disease control and public health in general $[1,2]$. In Low to Middle Income Countries (LMIC) like Guatemala antibiotics are sold essentially as over-thecounter medications. In addition to easy access of antibiotics, self-medication is highly prevalent in LMIC and Organization for Economic Co-operation and Development (OECD) countries although no patterns in the characteristics of those who self-medicate have been established [3,4]. What is clear, is that patients practicing self-medication in LMIC are often unaware of potential problems that may arise [5] including side 
effects, antimicrobial resistance, or worsening of symptoms. [6-9] Additionally, self-medicating individuals don't have pertinent information regarding medications' side effects and dosing instructions $[10,11]$. These problems are to be expected in self-medicating patients given that patients often obtain medication advice from nonprofessionals [3], family and friends [12]. In these cases self-medication may lead to irrational use, poor adherence to regimens, side-effects and overuse of antibiotics.

Evidence shows excessive self-medication practice in Latin America $[6,7,13,14]$ but data indicating types of drugs and factors associated with self-medication is limited and often contradictory. In Argentina, Brazil, Chile, Colombia, Costa Rica, and Nicaragua, authors attributed the high prevalence of self-medication to poor access to health care services [13]. In Peru there were no significant differences in self-medication practices associated with gender, occupation, educational level or being head of the household [14]. In Honduras, higher proportions of self-medicating patients have been reported among those living in urban areas, but socio-economic status was not associated with self-medication [6].

Evidence regarding self-medication and its relationship to educational level and socio-economic status is mixed. In Peru, authors found that education had no significant effect on self-medication [14], while two studies in Sudan and one in Jordan found that self-medication was associated with higher literacy levels [15-17]. In one European study, higher educational level predicted higher selfmedication rates [4]. Educational level does not clearly predict proportions of those who self-medicate, the same is true for socio-economic status where data is inconsistent among groups. In Jordan, one study showed positive association between self-medication and low income [17]; in Syria, patients with a middle income more frequently self-medicated [8], whereas in the United Arab Emirates there was no association to income but rather selfmedication was related to ethnicity [18].

In addition to the varying data surrounding characteristics of those who self-medicate, the official health system has been ambiguous and contradictory about self-medication, recommending it in some cases while challenging it in others [19]. Multiple factors facilitate high prevalence of self-medication, such as poor access to health care providers, low quality of health services, high costs of medications, absence of regulations regarding the promotion and sale of medications, easy access in pharmacy outlets without a prescription, and publicity of pharmacy chains [20].

In Latin America pharmacists have shown interest in participating in patient-care to aid in safe medication practice [21], which may be more effective in curbing antibiotic misuse when the characteristics of selfmedication with antibiotics are better understood. In order to design these types of educational interventions in the community it is important to understand the environment surrounding the practice of self-medication: motives for self-medicating, ways of self-medicating, and characteristics of those who self-medicate.

In this study we aimed to compare the magnitude of antibiotic self-medication and the characteristics of those who self-medicate with antibiotics in two pharmacies serving disparate socio-economic communities in Guatemala City.

\section{Methods}

From May to August of 2013 we carried out a descriptive cross-sectional study in two pharmacies in Guatemala City. We used purposeful sampling to select two private pharmacies serving different segments of the population according to key informants from pharmacy staff members. The first pharmacy was located in San Cristobal (zone 8 of Mixco, according to the local nomenclature), a suburb that is part of the city's metropolitan area serving clients characterized as professional or executive employees with higher levels of education and higher purchasing power. The second pharmacy, located in historical City Center (zone 1, using the local nomenclature), serves clients generally characterized as being working class and with lower levels of education and lower purchasing power.

Sample size was calculated for each pharmacy using Epidat 4.0 based on a population of 350 patients arriving to the pharmacy weekly, assuming that $50 \%$ of the population self-medicates, a precision of $5 \%$ and a $95 \%$ confidence level. Customers who purchased antibiotics without a prescription were invited to participate in the study. Written informed consent was obtained and participants were given a brief verbal definition of the practice of self-medication and the opportunity to ask any questions regarding the study or self-medication with antibiotics. Participants were asked to complete the questionnaire, which consisted of a brief introduction of study objectives and a definition of self-medication: "Self-medication occurs when patients obtain and use medications without a prescription from a doctor, meaning that patients make a personal decision to seek treatment for their illness." We determined which antibiotics were being used for self-medication by documenting the generic name of the antibiotic at the time the participant purchased the medication. Potential participants were excluded from the study if they were less than 16 years old, had seen a doctor that day, were already taking antibiotics, belonged to a vulnerable population (HIV positive, elderly or underage), were under the influence of alcohol or drugs, and/or did not understand Spanish.

Data was collected by a questionnaire [1] that was designed based on instruments used in previous studies 
$[10,22,23]$. The questionnaire was validated by interviewing approximately 20 customers with the aim of detecting comprehension problems and to assess if the questions responded to the research aims. The instrument consisted of 22 questions: 21 multiple choice and 1 open ended question. Multiple responses were allowed for the following items: 1) Respondent symptoms provoking self-medication, 2) Reasons for self-medicating, and 3) Locations where respondents purchased antibiotics for self-medicating. We gathered information about frequency of self-medication, symptoms that provoked self-medication, with which antibiotics patients selfmedicated, whom they went to for advice upon selfmedicating, and if they read the antibiotic information handout. We defined antibiotics as the following: medications that treat bacterial and protozoal infections, and that are found on the World Health Organization's (WHO) Model list of Essential medicines and on the Guatemalan national "basic list" of medications [24,25]. The questionnaire was administered in a private area of the pharmacy from May to August of 2013, Monday through Friday between the hours of 9 am and $4 \mathrm{pm}$ (until the target number of questionnaires were obtained). Participants were given the option of selfadministering the questionnaire or having the researcher register their responses through verbal response.

Data analysis compared proportions of self-medication between the two pharmacies, using two-sample z-test as appropriate. The Research Ethics Committee at the Universidad del Valle de Guatemala approved all research materials before the study began.

\section{Results}

\section{Socio-demographic characteristics}

A total of 418 people responded to the survey, 221 in the Suburban pharmacy and 197 in the City Center pharmacy, with approximately $70 \%$ of participants self-administering the questionnaire. The majority of participants in the Suburban pharmacy and City Center pharmacy were female $(70 \%)$ and between the ages of 20-29 years old (28\%, 39\% respectively).

Although the majority of study participants were salaried employees (62\% Suburban pharmacy, 55\% City Center), there was a marked difference between pharmacies when looking at the monthly income and educational level. In the Suburban pharmacy the monthly income of participants was between $\$ 1,334.00-\$ 2,666.00$, whereas in the City-Center pharmacy the monthly income was between $\$ 0.00$ - $\$ 667.00$ ( $p<0.01)$. The proportion of respondents who had completed a high school education was $27 \%$ in the Suburban pharmacy and 3\% in the City Center pharmacy $(p<0.01)$. The demographic characteristics of the respondents are shown in Table 1.

\section{Magnitude of self-medication}

The proportion of self-medication with antibiotics was high in both pharmacies: $79 \%$ in the Suburban pharmacy and $77 \%$ in City Center pharmacy. The two primary reasons for self-medicating in both pharmacies were time constraints for doctors' visits (38\% Suburb, 56\% City Center $\mathrm{p}<0.01$ ) and purchasing convenience (27\% Suburb, $17 \%$ City Center). Frequency of self-medication differed between pharmacies. Suburban pharmacy participants reported selfmedicating once a month (35\%) or once a year (30\%). In contrast City Center pharmacy respondents reported selfmedicating once a week (33\%) or once a year (34\%). Although many respondents claimed to buy medications several times a year, most reported seeing a doctor only once a year (City Center 48\%, Suburban pharmacy 51\%).

In both settings, amoxicillin was most commonly purchased for self-medication, followed by tetracycline and sulfamethoxazole/trimethoprim, as it is detailed in Table 2. Flu-like symptoms were the most common reason for self-medicating in the Suburban and City Center pharmacy (33\%, 32\%, respectively), followed by fever and pain as shown in Table 3.

\section{Characteristics of self-medication}

In the Suburban pharmacy, respondents purchased selfmedicating products in pharmacies (77\%) and supermarkets (9\%). In the City Center pharmacy, the majority of respondents purchased antibiotics in pharmacies (70\%) followed by neighborhood stores (or "tiendas" in Spanish) (29\%).

Participants were asked to rate, on a scale of 1-10, the effect self-medication could have on one's health (1 being a negative effect and 10 being a positive effect). The majority of respondents, $63 \%$ of Suburban and $65 \%$ of City Center participants, responded marking 6 and above, perceiving little or no negative effect in selfmedication (see Table 3).

Participants from both pharmacies obtained information regarding self-medication with antibiotics through advice rather than by reading patient handouts. In the Suburban pharmacy, respondents sought advice from pharmacy technicians (38\%), followed by family (36\%) and friends (23\%). In contrast, City Center respondents spoke with family members $(65 \%)$ or friends $(30 \%)$ while only $4 \%$ went to pharmacy employees for advice. A large majority of respondents in both the Suburban and City Center pharmacies indicated that they did not read the instructions or the patient handout accompanying the antibiotic before self-medicating $(80 \%$ and $95 \%$, respectively). These findings are summarized in Table 3.

\section{Discussion}

High proportions of self-medication were similar in both pharmacies, despite the differences in monthly income 
Table 1 Demographics of self-medication survey respondents visiting two pharmacies in the Guatemala City area

\begin{tabular}{|c|c|c|}
\hline Basic demographics & $\begin{array}{l}\text { \# Suburb } \\
n=221,(\%)\end{array}$ & $\begin{array}{l}\text { \# City center } \\
\mathrm{n}=197,(\%)\end{array}$ \\
\hline \multicolumn{3}{|l|}{ Age } \\
\hline 16-19 & $14(6 \%)$ & $15(7 \%)$ \\
\hline $20-29$ & $63(29 \%)$ & 77 (39\%) \\
\hline 30-39 & $59(27 \%)$ & $45(23 \%)$ \\
\hline $40-49$ & $43(19 \%)$ & $25(13 \%)$ \\
\hline 50 and above & $42(19 \%)$ & $35(18 \%)$ \\
\hline \multicolumn{3}{|l|}{ Gender } \\
\hline Female & $155(70 \%)$ & 137 (70\%) \\
\hline Male & $66(30 \%)$ & $60(30 \%)$ \\
\hline \multicolumn{3}{|l|}{ Marital Status } \\
\hline Married & $124(56 \%)$ & $88(45 \%)$ \\
\hline Single & $28(13 \%)^{*}$ & $53(27 \%)^{*}$ \\
\hline Other & $69(31 \%)$ & $56(28 \%)$ \\
\hline \multicolumn{3}{|l|}{ Educational level } \\
\hline Less than Middle School & $60(27 \%)^{*}$ & $131(66 \%)^{*}$ \\
\hline Middle School Education & $55(25 \%)$ & $52(26 \%)$ \\
\hline High School Education & $59(27 \%)^{*}$ & $6(3 \%)^{*}$ \\
\hline College Education & $47(21 \%)^{*}$ & $8(4 \%)^{*}$ \\
\hline \multicolumn{3}{|l|}{ Income } \\
\hline$\$ 0-\$ 667$ & $95(43 \%)^{*}$ & $153(77 \%)^{*}$ \\
\hline$\$ 668-\$ 1,333$ & $38(17 \%)^{*}$ & $9(5 \%)^{*}$ \\
\hline$\$ 1,334-\$ 2,666$ & $88(40 \%)^{*}$ & $35(18 \%)^{*}$ \\
\hline \multicolumn{3}{|l|}{ Occupation } \\
\hline House wife & $45(20 \%)$ & $49(25 \%)$ \\
\hline Salaried employee & $138(62 \%)$ & 108 (55\%) \\
\hline Independent worker & $22(10 \%)$ & $17(8 \%)$ \\
\hline Other & $16(7 \%)$ & $23(12 \%)$ \\
\hline
\end{tabular}

and educational level. This differs with findings in other studies. One comparative study in Brazil documented a higher prevalence of self-medication in higher socioeconomic classes versus lower socio-economic classes; higher socio-economic patients paid out of pocket for their medications and lower socio-economic patients had free access to medication. In this Brazilian study, paying for medications was a positive factor associated to self-medication [26]. Another study in Mexico showed that low socio-economic status and lower educational level were positively associated to self-medication [11]. Practices in self-medication and their relation to socioeconomic status have been defined in these settings, but to our knowledge this has not been previously established in Guatemala. Our findings suggest that self-medication with antibiotics in this urban Guatemala City setting is high despite differences in monthly income and educational level.

More women came to pharmacies to self-medicate with antibiotics than men in both settings. This is similar to a recent study carried out in Chile whose findings indicated that $73 \%$ of those who self-medicated were female [10]. The high proportion of females who selfmedicate has also been reported in several LMIC, OECD and European countries [3] with the exception of Nepal, Syria and the United Arab Emirates [8,18,27]. In Mexico women have been reported to self-medicate themselves or their children more often than men, in this context, authors agreed that women should be targeted in healtheducation campaigns [7]. One study in rural Peru interviewed heads of the household in order to understand characteristics surrounding those who self-medicate. The head of the household was predominately male and responded more frequently to the questionnaire, however, there was no significant association found between gender and self-medicating practices [14]. The patterns of women who self-medicate are unknown in rural areas of Guatemala, in other urban areas outside of Guatemala City, and in areas with high proportions of indigenous people who do not use Spanish as their first language. These factors may affect the proportion of men and women who obtain medications from the pharmacy in order to self-medicate. Further investigation regarding gender and self-medication is warranted in Guatemala given that the gender of those who self-medicate may vary based on pharmacy and socio-cultural practices of each region.

We found that participants of a lower socio-economic status go to family or friends for advice when selfmedicating, whereas those of a higher socio-economic status more frequently talk to a pharmacy technician although they also rely on family. In a recent review of 70 studies looking at self-medication, 8 studies cited family as the major source of information for those who self-medicate. Seven studies cited friends and only 6 studies recorded pharmacists as the primary source of drug-information [3]. A recent study in older Mexican participants showed that respondents seek out advice first from family (30\%), followed by a pharmacist (27\%) [11]. In Guatemala we see a significant difference in whom participants are willing to approach for advice based on their socio-economic status. These findings would likely be important when designing educational programs aiding participants in the selection of selfmedication.

The majority of respondents in both pharmacies indicated that self-medication has a positive effect on their health. Previous studies have emphasized the dangers in self-medicating with antibiotics. Side effects, incorrect 
Table 2 Number of respondents purchasing antibiotics when self medicating

\begin{tabular}{|c|c|c|c|c|}
\hline \multirow{2}{*}{$\begin{array}{l}\text { Antibiotic purchased for } \\
\text { use in self-medication }\end{array}$} & \multicolumn{2}{|l|}{ Suburb $(n=221)$} & \multicolumn{2}{|l|}{ City center $(n=197)$} \\
\hline & Number of respondents & $\%$ & Number of respondents & $\%$ \\
\hline Amoxicillin & 114 & 51.58 & 82 & 41.62 \\
\hline Tetracycline & 34 & 15.38 & 55 & 27.92 \\
\hline Trimethoprim-sulfamethoxazol & 13 & 5.88 & 20 & 10.15 \\
\hline Erithromycin & 11 & 4.98 & 18 & 9.14 \\
\hline Ciprofloxacin & 9 & 4.07 & 9 & 4.57 \\
\hline Cefadroxil & 0 & 0.00 & 4 & 2.03 \\
\hline Cefixime & 0 & 0.00 & 4 & 2.03 \\
\hline Amoxicilin/Clavulanic Acid & 9 & 4.07 & 3 & 1.52 \\
\hline Azithromycin & 5 & 2.26 & 2 & 1.02 \\
\hline Secnidazol & 8 & 3.62 & 0 & 0.00 \\
\hline Albendazol & 6 & 2.71 & 0 & 0.00 \\
\hline Metronidazol & 6 & 2.71 & 0 & 0.00 \\
\hline Levofloxacin & 3 & 1.36 & 0 & 0.00 \\
\hline Ceftriaxone & 2 & 0.90 & 0 & 0.00 \\
\hline Clarithromycin & 1 & 0.45 & 0 & 0.00 \\
\hline Total & 221 & 100 & 197 & 100 \\
\hline
\end{tabular}

drugs or dosages and antibiotic resistances are all factors that make the practice problematic $[1,7,28]$. Patient awareness surrounding the "how", "why" and "when" to use antibiotics as well as the risks involved in selfmedication with antibiotics may be created through educational initiatives. One study reviewed LMIC pharmacy interventions and placed an emphasis on the educational services pharmacists may provide in order to improve outcomes [9]. These types of services must go beyond classifying medication use as "good or bad" [29]. If educational services are to be implemented, they must be all-inclusive resulting in a comprehensive educational plan for those who self-medicate $[6,9,13]$. There must be support within the local health-system giving incentive to form sustainable educational programs in the community. The gender of those who self medicate, how the socio-economic status influences self-medication, with whom respondents are willing to go to for advice, and techniques by which participants receive information about self-medicating all contribute to developing educational and political movements to ensure the safety and efficacy of antibiotic use.

Participants in this study did not read the antibiotic information handout associated with the medications they purchased, regardless of their socio-economic status and educational level. Educational level plays an important role when deciding how to effectively design drug information for participants [9]. Informing patients about a medication's indications, posology and side effects using means other than patient handouts that accompany medications is an important challenge if antibiotic use is to be addressed. Although all participants had some level of schooling, patient handouts accompanying medications may be inadequate in Guatemala given that the majority of self-medicators did not have a secondary school education. Combining the risks of self-medication with the demographic data we have gathered, we provide a basis for initiating educational policies surrounding medication use in the urban setting of Guatemala.

The majority of respondents purchased antibiotics from pharmacies where antibiotics are sold in the absence of any medical regulation, contributing to irrational use and antimicrobial resistance. In most LMIC, the debate of antibiotic regulation skews towards authorization of unregulated vendors selling antibiotics in order to maintain reasonable access to medications [30,31]. Additionally, competing interests of the pharmaceutical industry and pharmacy chains promote unregulated use of antibiotics [30]. Nevertheless, restricted and regulated use of antibiotics is of public health concern both locally and for many globally recognized organizations [2,28].

There is currently no law in Guatemala requiring the continual presence of a pharmacist in the pharmacy. Trained health care professionals do not monitor the sale and dispensing of antibiotics in Guatemala in community pharmacies, and there is no law requiring a prescription for antibiotic use; prescriptions are only required for controlled substances. Both factors -absence of health care professionals in the pharmacy and lack of regulations- lead to irrational use of antibiotics and antimicrobial resistance. This presents an opportunity for 
Table 3 Characteristics of self-medication in two Guatemala City pharmacies

Number of respondents in

Symptoms resulting in self-medication ${ }^{+}$

Cold/flu

Pain

Fever

Stomach ache

Diarrhea

Allergy

Reasons for self-medicating ${ }^{+}$

Lack of time and to save time

Easily purchasable medications from pharmacies

Economic reasons (High costs of visits to doctor/Low cost of purchasing drugs)

Simple sign and symptom of a disease

Convenient (ease of curing perceived symptoms)

Lack of trust toward doctors

Locations for obtaining medications ${ }^{+}$

Pharmacies

Supermarket

Corner stores

From home (previously purchased)

Frequency of self-medication

One time per week

One time per month

Two times per month

Every two months

Every three months

Every six months

Two times per year

One time per year

Never

Regarding the antibiotic information handout

Do not read antibiotic information handout

Read antibiotic information handout

How it can effect one's health, 1 negative effect 10 positive effect

1 on a scale of 10
$2-4$ on a scale of 10
5 on a scale of 10
6 on a scale of 10
7 on a scale of 10
$8-10$ on a scale of 10

Who respondents go to for advice

Pharmacy employee

Family

Friend

Other
Suburb $(n=221)$

74 (33\%)

Number of respondents in City Center $(n=197)$

$66(30 \%)$

65 (33\%)

$39(18 \%)$

$54(27 \%)$

$22(10 \%)$

$41(21 \%)$

$26(13 \%)$

$10(5 \%)$

$5(3 \%)$

$10(4 \%)$

6 (3\%)

$84(38 \%)^{*}$

$110(56 \%)^{*}$

60 (27\%)

34 (17\%)

34 (15\%)

29 (15\%)

$20(9 \%)$

18 (9\%)

$18(8 \%)$

$3(2 \%)$

$4(2 \%)$

$3(2 \%)$

172 (77\%)

139 (70\%)

$20(9 \%)^{*}$

$0(0 \%)^{*}$

$19(8 \%)^{*}$

$58(29 \%)^{*}$

$9(4 \%)^{*}$

0*

42(19\%)*

65(33\%)*

$77(35 \%)^{*}$

$12(6 \%)^{*}$

1(0.5\%)

6(3\%)

$1(0.5 \%)$

2(1\%)

5(2\%)

$8(4 \%)$

$16(7 \%)$

21(11\%)

2(1\%)

66(30\%)

0

67(34\%)

$11(5 \%)$

$16(8 \%)$

$176(80 \%)^{*}$

$188(95 \%)^{*}$

$45(20 \%)^{*}$

$9(5 \%)^{*}$

$0(0 \%)^{*}$

$0(0 \%)^{*}$

37 (17\%)

$24(12 \%)$

45 (20\%)

35 (18\%)

67 (30\%)

40 (20\%)

42 (19\%)

46 (23\%)

$30(14 \%)$

44 (22\%)

$84(38 \%)^{*}$

$8(4 \%)^{*}$

$81(37 \%)^{*}$

$129(65 \%)^{*}$

52 (23\%)

60 (30\%)

$4(2 \%)$

$0(0 \%)$

*Significant difference between suburb and city center pharmacies, $\mathrm{p}<0.01$.

${ }^{+}$Multiple responses were allowed for these items. 
developing the role of the pharmacist in guiding the rational use of antibiotics in Guatemala where we have shown that a proportion of respondents seek advice from pharmacists. Fundamental to the policy development surrounding the role of a pharmacist is the establishment of associated laws regulating the dispensing of medications [14]. Relationships with other health care professionals, social pressures and conflicts of business and professional roles must be taken into account in this type of policy development [9]. Restructuring and eventual development of the role of the pharmacist may improve safe and rational use, affordability and accessibility of antibiotics in Guatemala $[9,12]$.

Limitations of this study include those inherent to the cross-sectional research design, as well as the use of purposeful sampling for selecting the pharmacies. The study is not population-based and therefore its results cannot be assumed to be generalizable to all pharmacies in Guatemala City or to Guatemala City. The study did not ask qualitative questions that allowed participants to provide their own explanations and meanings around self-medication.

The results of our study contribute to a better understanding of why people self-medicate, the characteristics of those who self-medicate and how people self-medicate in Guatemala and should be complemented with further investigations that include pharmacies located in other urban and rural settings. It is also important to determine which, if any, side effects participants may experience as a result of self-medicating with antibiotics and if their perceived risk of self-medication changes across rural versus urban settings. Also, it may be important to know if participants perceive self-medication as "curative" or, if as a result of their practice, they have to see a physician to improve health outcomes. Additionally, further studies may focus on health literacy and the health systems dimensions of this problem.

\section{Conclusions}

The high proportion and factors contributing to selfmedication with antibiotics in Guatemala City are similar in two disparate socio-economic pharmacies. In this setting, women come to the pharmacy more often than men in order to self-medicate and perceive little risk in its practice. Those of higher socio-economic status in Guatemala City are willing to speak to pharmacy personnel for advice regarding self-medication and, although future studies are necessary, this study sets the stage for future policy development regarding the role of the pharmacist in addressing self-medication with antibiotics. This type of role, however, may have a limited public health impact if there are no changes in the regulation of antibiotic promotion, sale and use in Guatemala.

\section{Additional file}

Additional file 1: Antibiotic self-medication questionnaire_Spanish.

\section{Competing interests}

The authors declare that they have no competing interests.

\section{Authors' contributions}

BR supervised study design and data interpretation, conceptualized the article, drafted the manuscript, and coordinated review of co-authors. $\mathrm{PL}$ designed the study, conducted interviews, processed and analyzed data, and reviewed and revised the manuscript. AC contributed to the conceptualization of the article and data interpretation, and advised the development of the manuscript. All authors read and approved the final manuscript.

\section{Acknowledgements}

$\mathrm{BR}$ and $\mathrm{PL}$ covered research costs, with logistic support from Universidad del Valle de Guatemala. Dr. Elfego Rolando Lopez gave input to early versions of this manuscript. Dr. Carrie Coates and Rochelle Ramay, MA, edited final versions of the manuscript. Institutional support from the Center for the Study of Equity and Governance in Health Systems (CEGSS) was fundamental for developing the collaboration between $\mathrm{BR}$ and $\mathrm{AC}$ that led to the completion of this manuscript.

\section{Author details}

${ }^{1}$ Department of Pharmaceutical Chemistry, Universidad del Valle de Guatemala, Guatemala City, Guatemala. ${ }^{2}$ Department of Anthropology, University of Denver, Denver, Colorado, USA

Received: 4 July 2014 Accepted: 15 April 2015

Published online: 27 April 2015

\section{References}

1. World Health Organization. Antimicrobial Resistance Global Report on Surveillance. Geneva, Switzerland: World Health Press; 2014.

2. World Health Organization, Health Action International global. The World Medicines Situation 2011 Rational Use of Medicines, $3^{\text {rd }}$ edition. Geneva Switzerland: WHO Press; 2011.

3. Ahaghaghi A, Asadi M, Allahverdipour H. Predictors of Self-Medication Behavior: A Systematic Review. Iran J Publ Health. 2014;43:136-46.

4. Grigoryan L, Haaijer-Ruskamp FM, Burgerhof JGM, Mechtler R, Deschepper R, Tambic-Andrasevic A, et al. Self-medication with Antimicrobial Drugs in Europe. Emerg Infect Dis. 2006;12:452-9.

5. Stosic R, Fiona D, Hazel P, Fowler T, Adams I. Responsible self-medication: perceived risks and benefits of over-the-counter analgesic use. Int J Pharm Pract. 2011;19:236-45.

6. Crigger NJ, Grogan RL. Development of the choices and acquisition of antibiotics model from a descriptive study of a lay Honduran population. Int J Nurs Stud. 2004;41:745-53.

7. Angeles P, Maria Luisa M, Juan Francisco M. Automedicacion en poblacion urbana de Cuernavaca. Salud Publica Mex. 1992;34:554-61.

8. Barah F, Morris J, Gonçalves V. Irrational use and poor public beliefs regarding antibiotics in developing countries: a pessimistic example of Syria. Int J Clin Pract. 2009;63:1263-4

9. Smith F. Private local pharmacies in low- and middle-income countries: a review of interventions to enhance their role in public health. Trop Med Int Health. 2009;14:362-72.

10. Fuentes Albarrán K, Villa Zapata L. Analysis and quantification of self-medication patterns of customers in community pharmacies in southern Chile. Pharm World Sci. 2008;6:863-8.

11. Balbuena FR, Aranda AB, Figueras A. Self-Medication in Older Urban Mexicans: An Observational, Descriptive, Cross-Sectional Study. Drugs Aging. 2009:26:51-60.

12. Sonam J, Reetesh M, Jeetendra Kumar P. Concept of Self Medication: A review. Int J Pharm Biol Arch. 2011;2:831-6.

13. Drug Utilization Research Group, Latin America WHO. Multicenter study on self-medication and self-prescription in six Latin American Countries. Clin Pharmacol Ther. 1996;61:488-93 [4]. 
14. Llamos Zavalaga LF, Contreras Rios C, Velasquez Hurtado J, Mayca Perez J, Lecca Garcia L, Reyes Lecca R, et al. Automedicacion en cinco provincias de Cajamarca. Rev Med Hered Online. 2001;12:127-33.

15. Awad Al, Eltayeb IB, Capps PA. Self-medication practices in Khartoum State, Sudan. Eur J Clin Pharmacol. 2006;62:317-24.

16. Abdelmoneim A, Idris E, Lloyd M. Self-medication with Antibiotics and Antimalarials in the community of Khartoum State, Sudan. J Pharm Pharm Sci. 2005:8:326-31.

17. Al-Azzam S, Al-Husein B, Alzoubi F, Masadeh M, Al-Horani MA. Self-Medication with Antibiotics in Jordanian Population. Int J Occup Med Environ Health. 2007;20:1232-087.

18. Abasaeed A, Vlcek J, Abuelkhair M, Kubena A. Self-medication with antibiotics by the community of Abu Dhabi Emirate, United Arab Emirates. J Infect Dev Ctries. 2009;3:491-7.

19. Mendez E. Modelos de atención de los padecimientos: de exclusiones teóricas y articulaciones prácticas. Cienc Saude Colect. 2003;8:185-207.

20. Versporten A, Bolokhovets G, Ghazaryan L, Abilova V, Pyshnik G, Spasojevic $T$, et al. Antibiotic use in eastern Europe: a cross-national database study in coordination with the WHO Regional Office for Europe. Lancet Infect Dis. 2014;14(5):381-7.

21. Dupotey Varela NM, Oliveira DR D, Sedeño Argilagos C, Oliveros Castro K, Mosqueda Pérez E, Hidalgo Clavel Y, et al. What is the role of the pharmacist?: physicians' and nurses' perspectives in community and hospital settings of Santiago de Cuba. Braz J Pharm Sci. 2011;47:709-18.

22. Fuentes Albarrán K, Villa I, Mller C. Análisis y cuantificación de los patrones de automedicación en usuarios de farmacias Salcobrand de Valdivia. Undergraduate Thesis Universidad Austral de Chile; 2006. p. 1-66.

23. Tobon Marulanda FA. Estudio sobre la automediaccion en La Universidad de Antioquia, Medellin Colombia. latreia. 2002;15:242-7.

24. WHO. Model List of Essential Medicines, 18th list. Geneva Switzerland: WHO Press; 2013.

25. Ministerio de Salud Publica y Asistencia Social, Viallavicencio JA, Galvan MG, Sandoval WE, Arevalo MV, et al. Lista basica de medicamentos. Guatemala: MSPAS; 2013.

26. Schmid B, Bernal R, Silva NN. Self-medication in low-income adults in Southeastern Brazil. Rev Saúde Pública. 2010;44:2-6.

27. Shankar PR, Partha P, Shenoy N: Self-medication and non-doctor prescription practices in Pokhara valley, Western Nepal: a questionnaire-based study. BMC Fam Pr 2002, 3

28. Kelley PW. Antimicrobial resistance in the age of noncommunicable diseases. Rev Panam Salud Publica. 2011;30(6):515-8.

29. Fainzang S. Managing Medicinal Risks in Self-Medication. Drug Saf 2014;37:333-42.

30. Dreser A, Vázquez-Vélez E, Treviño S, Wirtz VJ. Regulation of antibiotic sales in Mexico: an analysis of printed media coverage and stakeholder participation. BMC Public Health. 2012;12:1051.

31. Carlet J, Pittet D. Access to antibiotics: a safety and equity challenge for the next decade. Antimicrob Resist Infect Control. 2013;2:1.

\section{Submit your next manuscript to BioMed Central and take full advantage of:}

- Convenient online submission

- Thorough peer review

- No space constraints or color figure charges

- Immediate publication on acceptance

- Inclusion in PubMed, CAS, Scopus and Google Scholar

- Research which is freely available for redistribution 